2010

\title{
Optimal Design of Trusses With Geometric Imperfections
}

\author{
Mehdi Jalalpour \\ Cleveland State University, m.jalapour@csuohio.edu \\ Takeru Igusa \\ Johns Hopkins University \\ James K. Guest \\ Johns Hopkins University, jkguest@jhu.edu
}

Follow this and additional works at: https://engagedscholarship.csuohio.edu/encee_facpub

Part of the Civil Engineering Commons, and the Structural Engineering Commons How does access to this work benefit you? Let us know!

\section{Original Citation}

Jalalpour, M., Igusa, T., Guest, J.K. "Optimal design of trusses with geometric imperfections", 13th AIAA/ISSMO Multidisciplinary Analysis and Optimization Conference, Fort Worth, Texas, 2010.

This Conference Proceeding is brought to you for free and open access by the Civil and Environmental Engineering at EngagedScholarship@CSU. It has been accepted for inclusion in Civil and Environmental Engineering Faculty Publications by an authorized administrator of

EngagedScholarship@CSU.For more information, please contact library.es@csuohio.edu. 


\title{
Optimal Design of Trusses With Geometric Imperfections
}

\author{
Mehdi Jalalpour ${ }^{1}$, Takeru Igusa, ${ }^{2}$ and James K. Guest ${ }^{3}$ \\ Department of Civil Engineering, Johns Hopkins University, Baltimore, MD 21218
}

\begin{abstract}
The present paper focuses on optimization of trusses that have randomness in geometry that may arise from fabrication errors. The analysis herein is a generalization of a perturbation approach to topology optimization under geometric uncertainties. The main novelty in the present paper is in the consideration of potential buckling due to misaligned structural members. The paper begins with a brief review of the aforementioned perturbation approach, then proceeds with the analysis of the nonlinear effects of geometric imperfection. The paper concludes with some numerical examples.
\end{abstract}

\section{Introduction}

$\mathrm{T}$

here is considerable literature on the optimization of truss structures, and the papers of interest herein are related to buckling. One approach for resisting buckling is through the use of local buckling constraints formulated in terms of the allowable Euler buckling stress (Neves et al. ${ }^{1}$, Bin-Tal et al. ${ }^{2}$, and Stolpe ${ }^{3}$ ). It has been found, however, that such a stress formulation poses numerical and other difficulties to the problem (Duysinx ${ }^{4}$, Kirsch ${ }^{5}$, Guo et al. ${ }^{6}$ and Rozvany ${ }^{7}$ ). For instance, Guo et al. ${ }^{6}$ mentions that this would subdivide the feasible domain into disjoint subdomains. They have proposed stress relaxation and other methods to overcome this difficulty. Rozvany ${ }^{7}$ argues that some unstable solutions can arise, as shown below in Fig. 1 where the ground structure is on the left and the design using standard optimization algorithms is on the right.
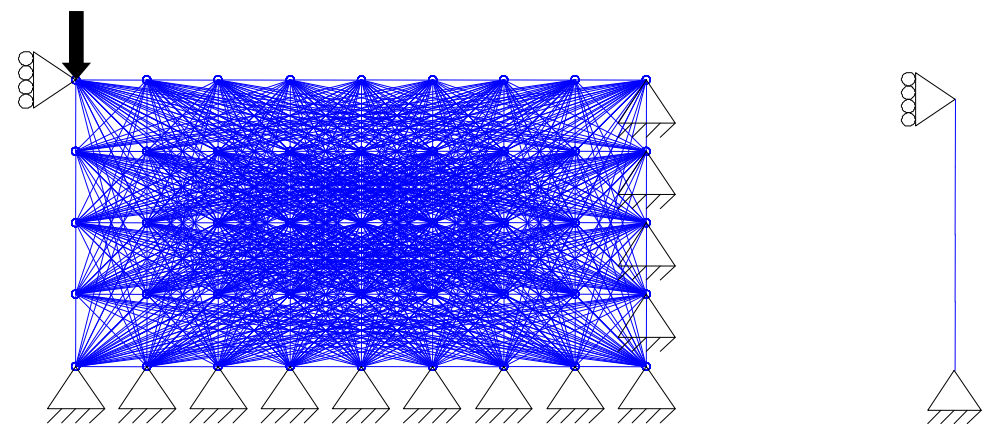

Figure 1. The solution reached by conventional optimizers (Inspired from Ref. 7)

The optimal solution is a 4 member column that is clearly kinematically unstable. It has been proposed in literature that node cancelation be applied to these types of problems. For the example in Fig. 1 the four elements are merged into one single column by removing the intermediate nodes. While this would remove the global instability problem, Zhou ${ }^{8}$ notes that the Euler buckling of such lengthened columns have not been considered in the design. Furthermore, if we did consider the Euler buckling of such lengthened columns in the algorithm, the cross sectional areas might become so large that solutions with shorter braced columns may be more economical. Rozvany $^{7}$ explored the use of system stability constraints and geometric imperfections to handle buckling in trusses. While he shows that the resulting designs are not truly optimal, they do include the kind of bracing needed to prevent global buckling behavior.

${ }^{1}$ PhD Student, Dept. Civil Engineering, Johns Hopkins University, Baltimore MD, and AIAA Student Member.

${ }^{2}$ Professor, Dept. Civil Engineering, Johns Hopkins University, Baltimore MD.

${ }^{3}$ Assistant Professor, Dept. Civil Engineering, Johns Hopkins University, Baltimore MD, and AIAA Member. 
In the present paper, we introduce geometric imperfections using random variables, and use a minimum expected compliance algorithm for topology optimization. Here, the expected compliance is the mean value of the structural compliance, which is a random variable that inherits statistical properties from the randomness of the geometric imperfections. In the following, we briefly review the development of the expected compliance formulation and associated optimization algorithm and then explain how it is extended to handle buckling in truss design.

This paper considers topology optimization where the goal is to identify the optimal distribution of material within a design domain that is subjected to loads and support boundary conditions. Unlike sizing optimization, which operates on a fixed structural connectivity, topology optimization allows for the introduction or removal of structural elements. The reader is referred to Ref. 9 for an introduction to topology optimization. Although straightforward in concept, topology optimization often exhibits some numerical difficulty associated with underlying governing mechanics, such as instability at the joints of trusses as mentioned in Refs. 1 and 2. Hence, topology optimization research has focused primarily on deterministic design problems, with the analysis of uncertainty typically limited to the loading (Bendsøe et al. ${ }^{10}$, Diaz and Bendsøe ${ }^{11}$, and Ben-Tal and Nemirovski ${ }^{12}$ ).

Uncertainties are important in design, particularly in optimized structures which tend to be light, slender and sensitive to manufacturing imperfections. A method for structural optimization with small uncertainty in nodal locations was recently proposed by Guest and Igusa ${ }^{13}$. Their approach to the problem was to transform the uncertainties in nodal locations to a set of equivalent random forces. They used second-order perturbations of the stiffness matrix to calculate these equivalent forces. Their structural optimization incorporated the compliance of the equivalent forces in the objective function. The extension to correlated uncertainties in the nodal locations was recently discussed in Asadpoure et al. ${ }^{14}$ If this methodology is applied to the truss in Fig. 1, the optimal design would have bracing, which would resist the flexibility introduced by the randomness in the nodal locations. It is noted that such bracing would also resist buckling, the buckling phenomena itself is not directly addressed in the objective function. This is indicated by the fact that the exact same amount of bracing would be present regardless of whether the applied loading is compressive or tensile.

The contribution of this paper is to modify the objective function proposed in Ref. 13 to introduce first order nonlinear effects associated with buckling so that the final resulting material distribution will be different under compressive and tensile forces. In this manner, the newly proposed method is capable of handling both nodal location uncertainty and, to first order, the buckling phenomena.

\section{Derivations}

Assume that node number $\mathrm{p}$ has randomness in location so the nodal coordinates can be stated as:

$$
\left(X_{p}, Y_{p}\right)=\left(X_{\mathrm{op}_{\mathrm{p}}}, Y_{0_{\mathrm{p}}}\right)+\left(\Delta X_{\mathrm{p}}, \Delta Y_{\mathrm{p}}\right)
$$

Here we will assume the following:

$$
\mathrm{E}\left[\Delta \mathrm{X}_{\mathrm{p}}\right]=\mathrm{E}\left[\Delta \mathrm{Y}_{\mathrm{p}}\right]=0 \text { and } \mathrm{E}\left[\Delta \mathrm{X}_{\mathrm{p}} \Delta \mathrm{Y}_{\mathrm{p}}\right]=0 \text { and } \mathrm{E}\left[\Delta \mathrm{X}_{\mathrm{p}}{ }^{2}\right]=\mathrm{E}\left[\Delta \mathrm{Y}_{\mathrm{p}}{ }^{2}\right]=\sigma^{2}
$$

The random forces corresponding to this random location can be defined similar to Ref. 13.

$$
\Delta \mathrm{F}_{\mathrm{X}}=-\mathrm{Q}_{\mathrm{p} 1} \mathrm{~d} \Delta \mathrm{X}_{\mathrm{p}} \text { and } \Delta \mathrm{F}_{\mathrm{Y}}=-\mathrm{Q}_{\mathrm{p} 2} \mathrm{~d} \Delta \mathrm{Y}_{\mathrm{p}}
$$

Where $Q_{p r}$ means the derivative of stiffness matrix with respect to random node $p$ location. In all the formula that follows the first subscript is the node number and the second is the direction. For example $\mathrm{Q}_{\mathrm{p} 2}$ means we are taking the derivative of the stiffness matrix with respect to direction y of node $\mathrm{p}$. $\mathrm{d}$ is the vector of displacement due to the real loads in global coordinates. $\Delta \mathrm{F}$ 's are random force vectors.

Now if we add the displacement due to these loads to the original perturbed structure we would get the new displacement vector as:

$$
\begin{gathered}
\Delta \mathrm{d}^{1}=\mathrm{e}_{\mathrm{p} 1} \Delta \mathrm{X}_{\mathrm{p}}+\left(-\mathrm{K}_{0}^{-1} \mathrm{Q}_{\mathrm{p} 1} \mathrm{~d} \Delta \mathrm{X}_{\mathrm{p}}\right)+\mathrm{e}_{\mathrm{p} 2} \Delta \mathrm{Y}_{\mathrm{p}}+\left(-\mathrm{K}_{0}^{-1} \mathrm{Q}_{\mathrm{p} 2} \mathrm{~d} \Delta \mathrm{Y}_{\mathrm{p}}\right) \\
\Delta \mathrm{d}^{1}=\left(\mathrm{e}_{\mathrm{p} 1}-\mathrm{K}_{0}^{-1} \mathrm{Q}_{\mathrm{p} 1} \mathrm{~d}\right) \Delta \mathrm{X}_{\mathrm{p}}+\left(\mathrm{e}_{\mathrm{p} 2}-\mathrm{K}_{0}^{-1} \mathrm{Q}_{\mathrm{p} 2} \mathrm{~d}\right) \Delta \mathrm{Y}_{\mathrm{p}}
\end{gathered}
$$


Here $\Delta \mathrm{d}^{1}$ is the vector of displacements which has random entrees, and $\mathrm{e}_{\mathrm{ij}}$ is a vector of zeros with a one at the degree of freedom which the derivative is taken with respect to. This means that now all DOF's have contributions from randomness in location.

To update the random forces we use this new displacement vector $\left(\Delta \mathrm{d}^{1}\right)$ to construct a new corresponding random force vector. We know that for every DOF with uncertainty we will have a vector of equivalent random forces, and the system is linear. Therefore, we can simply add the random forces that are corresponding to each DOF together, and construct a single random force vector using $\Delta \mathrm{d}^{1}$. The total random forces could be stated in a more compact form as follows:

$$
\Delta \mathrm{F}=-\sum_{\mathrm{i}=1}^{\text {Nodes }} \sum_{\mathrm{j}=1,2} \mathrm{Q}_{\mathrm{ij}} \mathrm{de}_{\mathrm{ij}}^{\mathrm{T}} \Delta \mathrm{d}^{1}=-\sum_{\mathrm{i}=1}^{\text {Nodes }} \sum_{\mathrm{j}=1,2} \mathrm{Q}_{\mathrm{ij}} \mathrm{de}_{\mathrm{ij}}^{\mathrm{T}}\left[\left(\mathrm{e}_{\mathrm{p} 1}-\mathrm{K}_{0}^{-1} \mathrm{Q}_{\mathrm{p} 1} \mathrm{~d}\right) \Delta \mathrm{X}_{\mathrm{p}}+\left(\mathrm{e}_{\mathrm{p} 2}-\mathrm{K}_{0}^{-1} \mathrm{Q}_{\mathrm{p} 2} \mathrm{~d}\right) \Delta \mathrm{Y}_{\mathrm{p}}\right]
$$

Observe that we now have forces at every DOF given only a single source of uncertainty. In order to simplify the notation that follows we will define for each of these sources (p):

$$
\alpha_{\mathrm{ij}}^{\mathrm{pk}}=\mathrm{e}_{\mathrm{ij}}^{\mathrm{T}}\left(\mathrm{e}_{\mathrm{pk}}-\mathrm{K}_{0}^{-1} \mathrm{Q}_{\mathrm{pk}} \mathrm{d}\right)
$$

The above two steps can be repeated to form a series expansion for $\alpha_{i j}^{p k}$ which rapidly converges. The superscript stands for node number and direction (for the sources of uncertainty).

$$
\Delta \mathrm{F}=-\sum_{\mathrm{i}=1}^{\text {Nodes }} \sum_{\mathrm{j}=1,2} \mathrm{Q}_{\mathrm{ij}} \mathrm{d}\left(\alpha_{\mathrm{ij}}^{\mathrm{p} 1} \Delta \mathrm{X}_{\mathrm{p}}+\alpha_{\mathrm{ij}}^{\mathrm{p} 2} \Delta \mathrm{Y}_{\mathrm{p}}\right)
$$

The compliance formula for the first order effects is:

$$
\mathrm{C}=\mathrm{f}^{\mathrm{T}} \mathrm{d}=\mathrm{f}^{\mathrm{T}} \mathrm{K}_{0}^{-1}(\mathrm{f}+\Delta \mathrm{F})+\Delta \mathrm{F}^{\mathrm{T}} \mathrm{K}_{0}^{-1} \Delta \mathrm{F}
$$

Plugging back equation (7) in the compliance formula results in:

$$
\mathrm{f}^{\mathrm{T}} \mathrm{d}=\mathrm{f}^{\mathrm{T}} \mathrm{K}_{0}^{-1}\left[\mathrm{f}-\sum_{\mathrm{i}=1}^{\mathrm{Nodes}} \sum_{\mathrm{j}=1,2} \mathrm{Q}_{\mathrm{ij}} \mathrm{de}_{\mathrm{ij}}^{\mathrm{T}} \Delta \mathrm{d}^{1}\right]+\left(\sum_{\mathrm{i}=1}^{\mathrm{Nodes}} \sum_{\mathrm{j}=1,2} \mathrm{Q}_{\mathrm{ij}} \mathrm{de}_{\mathrm{ij}}^{\mathrm{T}} \Delta \mathrm{d}^{1}\right)^{\mathrm{T}} \mathrm{K}_{0}^{-1} \sum_{\mathrm{r}=1}^{\mathrm{Nodes}} \sum_{\mathrm{s}=1,2} \mathrm{Q}_{\mathrm{rs}} \mathrm{de}_{\mathrm{rs}}^{\mathrm{T}} \Delta \mathrm{d}^{1}
$$

If we plug back the expression for $\Delta \mathrm{d}^{1}$, and $\alpha_{\mathrm{ij}}^{\mathrm{pk}}$ and take the expected value considering that $\mathrm{E}\left[\Delta \mathrm{X}_{\mathrm{p}} \Delta \mathrm{Y}_{\mathrm{p}}\right]=0$ we will get:

$$
\begin{aligned}
\mathrm{E}\left[\mathrm{f}^{\mathrm{T}} \mathrm{d}\right]= & \mathrm{f}^{\mathrm{T}} \mathrm{d}+\sigma^{2}\left(\sum_{\mathrm{i}=1}^{\text {Nodes }} \sum_{\mathrm{j}=1}^{2} \alpha_{\mathrm{ij}}^{\mathrm{p} 1} \mathrm{Q}_{\mathrm{ij}} \mathrm{d}\right)^{\mathrm{T}} \mathrm{K}_{0}^{-1} \sum_{\mathrm{r}=1}^{\text {Nodes }} \sum_{\mathrm{s}=1,2} \mathrm{Q}_{\mathrm{rs}} \mathrm{d} \alpha_{\mathrm{ij}}^{\mathrm{p} 1}+ \\
& \sigma^{2} \sum_{\mathrm{i}=1}^{\mathrm{Nodes}} \sum_{\mathrm{j}=1}^{2} \alpha_{\mathrm{ij}}^{\mathrm{p} 2}\left(\mathrm{Q}_{\mathrm{ij}} \mathrm{d}\right)^{\mathrm{T}} \mathrm{K}_{0}^{-1} \sum_{\mathrm{r}=1}^{\mathrm{Nodes}} \sum_{\mathrm{s}=1,2} \mathrm{Q}_{\mathrm{rs}} \mathrm{d} \alpha_{\mathrm{ij}}^{\mathrm{p} 2}
\end{aligned}
$$

$\mathrm{K}_{0}$ is the stiffness matrix of the unperturbed structure. More simplifications could be made if we define similar to Ref. $13 \delta f_{i j}=-Q_{i j} d$ as the equivalent deterministic forces, and $d_{i j}$ as the displacement due to the action of equivalent loads. The formula for compliance when node $\mathrm{p}$ has randomness in location in both directions would be:

$$
\mathrm{C}=\mathrm{E}\left[\mathrm{f}^{\mathrm{T}} \mathrm{d}\right]=\mathrm{f}^{\mathrm{T}} \mathrm{d}+\sigma^{2} \sum_{\mathrm{k}=1,2} \sum_{\mathrm{i}=1}^{\text {Nodes }} \sum_{\mathrm{j}=1}^{2} \alpha_{\mathrm{ij}}^{\mathrm{pk}} \delta \mathrm{f}_{\mathrm{ij}}{ }^{\mathrm{T}} \sum_{\mathrm{r}=1}^{\mathrm{Nodes}} \sum_{\mathrm{s}=1,2} \mathrm{~d}_{\mathrm{rs}} \alpha_{\mathrm{rs}}^{\mathrm{pk}}
$$

The problem could be stated as follows:

$$
\operatorname{Min}\left(\mathrm{C}\left(\mathrm{A}^{\mathrm{e}}\right)=\mathrm{E}\left[\mathrm{f}^{\mathrm{T}} \mathrm{d}\right]=\mathrm{f}^{\mathrm{T}} \mathrm{d}+\sigma^{2} \sum_{\mathrm{k}=1,2} \sum_{\mathrm{i}=1}^{\text {Nodes }} \sum_{\mathrm{j}=1}^{2} \alpha_{\mathrm{ij}}^{\mathrm{pk}} \delta \mathrm{f}_{\mathrm{ij}}{ }^{\mathrm{T}} \sum_{\mathrm{r}=1}^{\text {Nodes }} \sum_{\mathrm{s}=1,2} \mathrm{~d}_{\mathrm{rs}} \alpha_{\mathrm{rs}}^{\mathrm{pk}}\right)
$$




$$
\text { such that }\left\{\begin{array}{c}
A^{e} \geq 0 \\
f=K d \\
\delta f_{r s}=K d_{r s} \\
\sum A^{e} l^{e} \leq V_{\text {total }}
\end{array}\right.
$$

Design variables are the cross sectional areas of members. Also a generalization beyond a single node with randomness is straight forward if we assume that these random variables are uncorrelated. To do this we simply sum over the random nodes as well. In order to take the derivative of the objective function with respect to cross sectional areas we use the adjoint method.

The algorithm to implement could be summarized as:

1- Input geometry, loading, location of random nodes and the material properties.

2- Calculate the stiffness matrix of truss and calculate the vector of displacement due to real loading $\mathrm{d}$.

3- Fix d and calculate $\delta f_{i j}$ and $\mathrm{d}_{\mathrm{ij}}$.

4- Calculate the sensitivity of the objective function.

5- Optimize the structure subject to constraints and find the new value for cross sectional areas.

6- If not converged go to step 2.

\section{Numerical Examples}

To demonstrate the effectiveness of the proposed methodology several trusses have been modeled and analyzed. Let us start with a rather simple structure shown in Fig. 2.

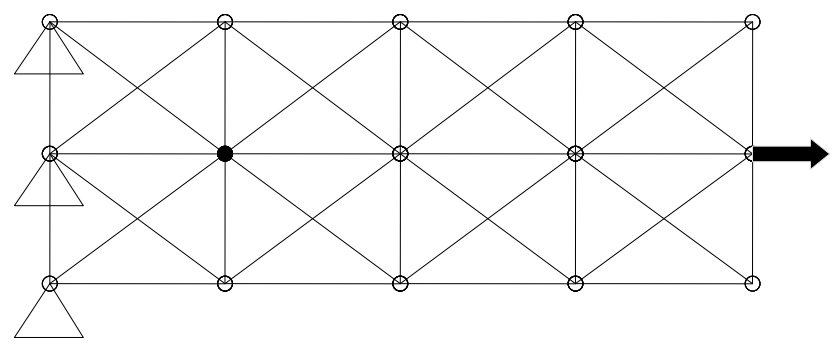

Figure 2. Ground structure for the first example (Inspired from Ref. 13)

The loading is applied on the single node and it could be either tension or compression. We consider only one node with randomness in location; this node is shown in bold in the figure. The standard deviation of randomness is considered to be 0.05 times the horizontal members' length. The lengths of vertical members are 0.75 times the horizontal ones. This structure could be viewed as column that has lateral bracing.

The final results after the optimization process has been completed are shown in Fig. 3. The numbers shown adjacent to each member are the relative cross sectional areas of that member. We can see the differences in the optimized structure layouts easily here. As expected, when the loading is in tension all material shifts towards the middle column and the lateral bracing vanishes from domain, leading to the solution without uncertainty considered. However if the loading is in compression we can see that some of the material is moved towards the bracing elements and less in the main load path (middle column). This arrangement is achieved to resist column buckling. Another interesting fact is that although only one node was assumed to have randomness, the final result for compression includes bracing at all nodes. This is consistent with the fact that buckling is a global and not a local phenomenon even when the geometric imperfection is limited to a single node. 


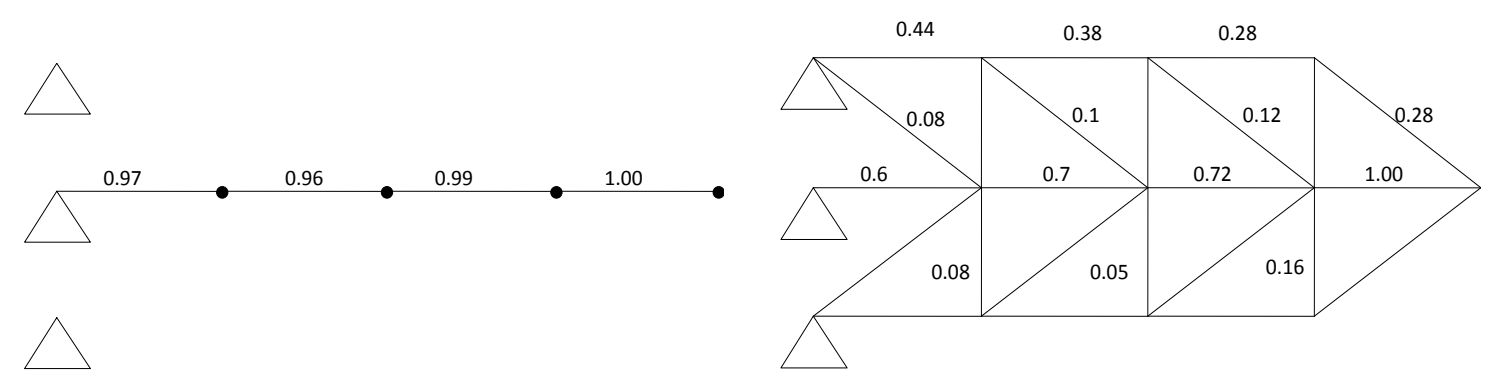

Figure 3. Optimized structure of example 1 for the tensile (left) and compressive force (Right)

Next we examine a square truss. The ground structure and load is shown in Fig. 4. The structure is symmetric with the left side under tension and the right side under compression. We consider geometric randomness at all nodes. The standard deviation of randomness is equal to 0.1 times the horizontal member lengths.

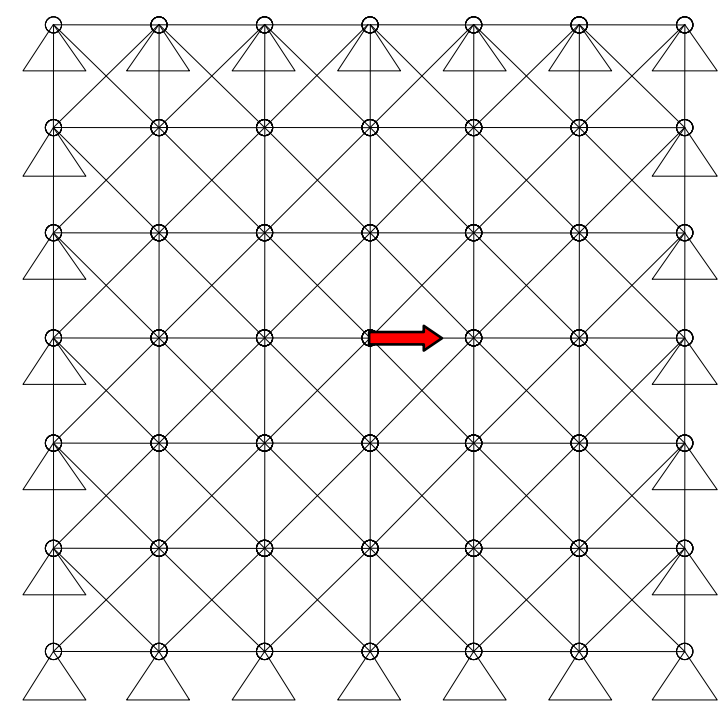

Figure 4. Ground structure for the second example

The results for two force magnitudes are shown in Fig. 5. The thickness of the members indicates their relative cross sectional areas. Three things are interesting in the results:

1- More material is in the tension side of the structure. This means that in the optimized structure more loading is transferred via tension.

2- For the larger force the design is a 3-member bar which has only members in the tension side.

3- The compression side has bracing, which is suitable to resist buckling 

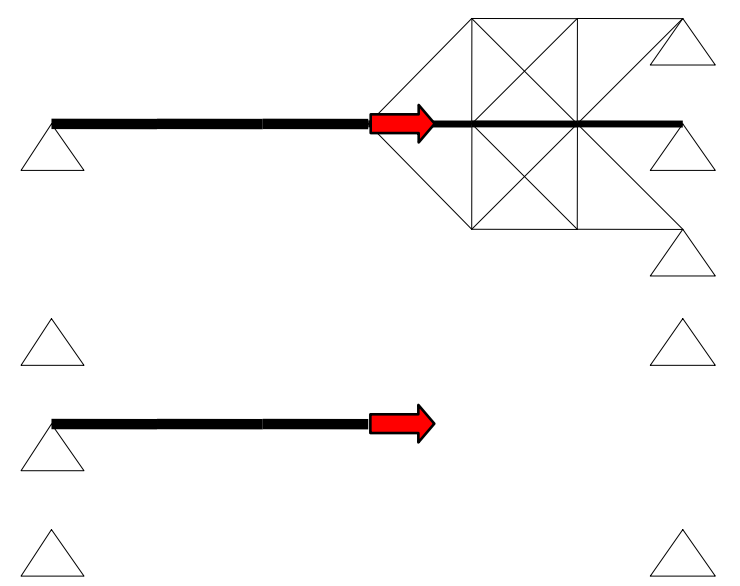

Figure 5. Changes in optimal topologies as the load magnitude increases for the square truss

The ground structure of the third example, shown in Fig. 6, is a cantilever structure. For this problem we will assume that all nodes have randomness in both directions. The vertical length is twice the horizontal and the randomness is 0.03 times the horizontal member lengths.

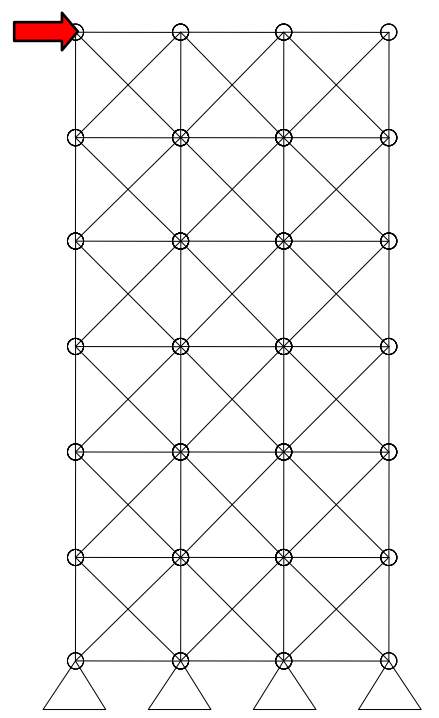

Figure 6. Ground structure for the third example

First we examine the optimal deterministic design shown in Fig. 7. We can see that this design is kinematically unstable unless we incorporate node cancelation. If we do use node cancelation, the long slender vertical column will be vulnerable to buckling, and a relatively high volume of material will be needed leading to a design which may not be economical. 


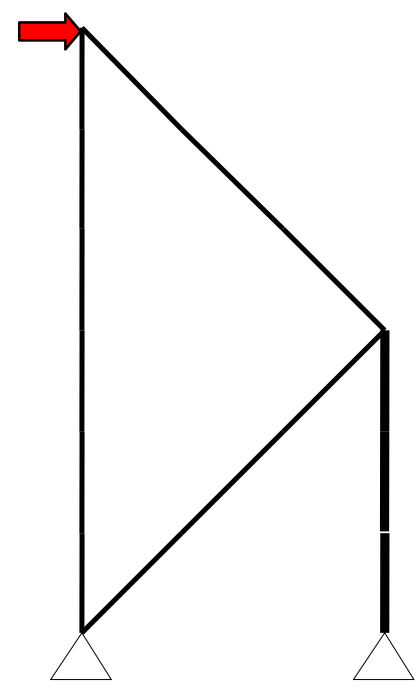

Figure 7. Deterministic solution to the cantilever structure

We will now optimize this structure using our proposed method. The final result is shown in Fig. 8. In this figure thicker elements have larger cross sectional areas.

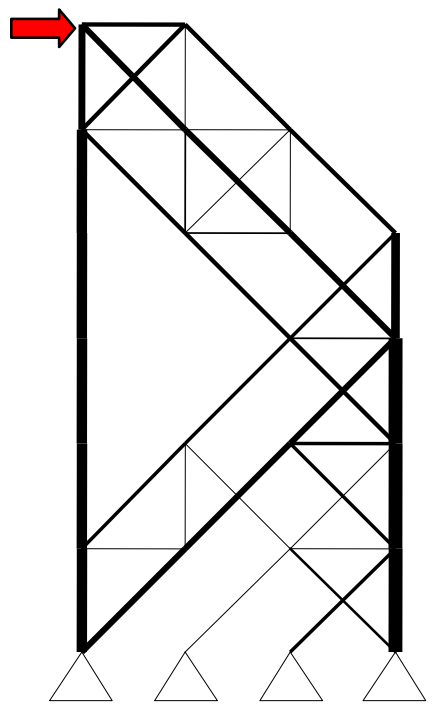

Figure 8. Optimal solution for cantilever structure

This new design reveals some interesting aspects. First, we note that the tension (left) side of the structure is not braced, while the compressive (right) side is braced to resist the potential buckling. Second, we can observe that additional load paths have evolved on the compression side. Finally, it is noted that these new load paths share some of the same bracing with the original (deterministic) load path. This lead to an economical use of the bracing.

Our next example is a somewhat more complex truss as shown in Fig. 9. This structure could be viewed as an Lshaped bracket. We can see that due to the applied loading, the outer layers of the structure transmits load under tension and the inner members carry loads in compression. Again we assume that randomness is present at every node with $\sigma=0.1$ times horizontal member lengths. The dimensions of the model are the same in both directions. 


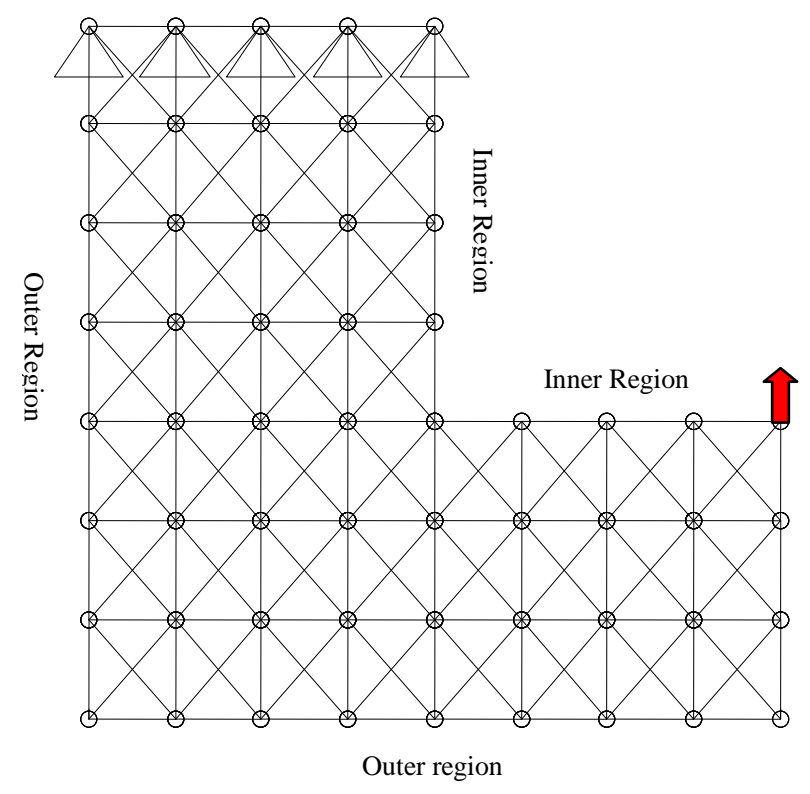

Figure 9. Ground structure for the L-shaped structure

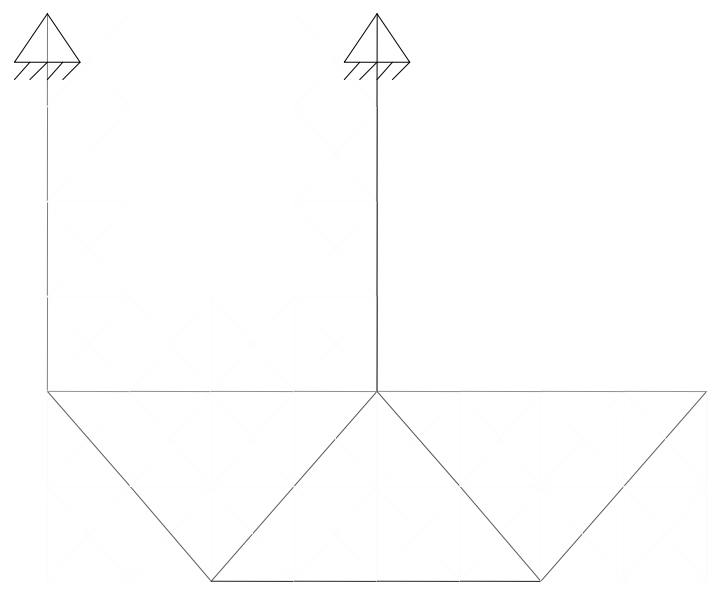

\section{Figure 10. Optimal deterministic solution for the L-shaped structure}

Figure 10 shows the optimized structure when no uncertainty is considered. Clearly this solution is kinematically unstable in which the compression column is not braced against potential buckling. The method of node cancelation is inadequate because of the global instability in the horizontal direction.

To find a better solution to this problem we will again optimize this structure using our proposed method. The result is shown in Fig. 11. It is clear that additional load paths have been evolved at the lower portion of the structure. The unbraced members at the left side are in tension, whereas the fairly densely braced members at the upper middle region (right column) are under compression. 


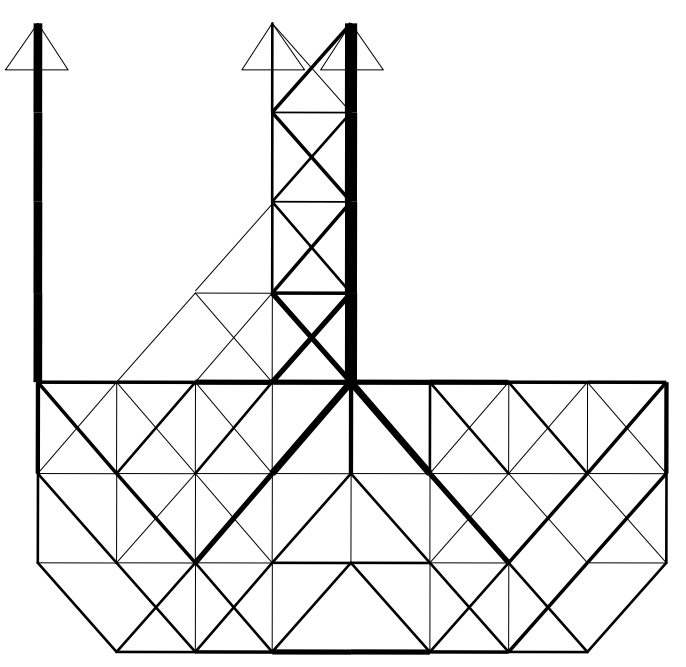

Figure 11. Final result for the L-Shaped structure

For the final example we consider the ground structure in Fig. 12. The height is 0.5 times the width and we assume randomness in all nodes equal to .05 times the length of the horizontal bays. Based on the geometry and loading, this structure is symmetric. The deterministic solution is shown in Fig. 13. We note that this design is also symmetric, and is similar to the well known result for the design of continuous cantilever (Ref. 9).

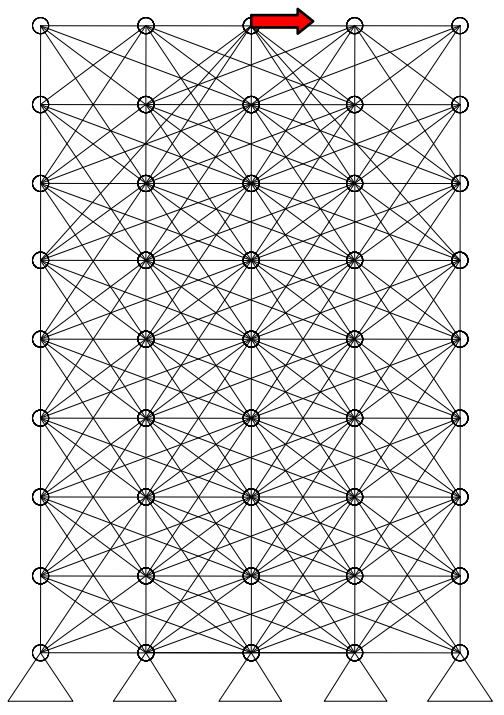

Figure 12. Ground structure for the final example 


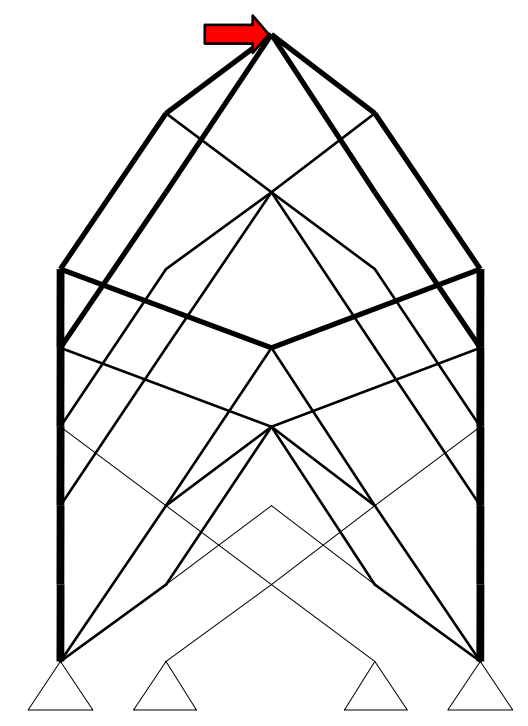

Figure 13. Deterministic solution for the last example

Then we optimize this structure considering randomness at all nodes; the final result is shown in Fig. 14.

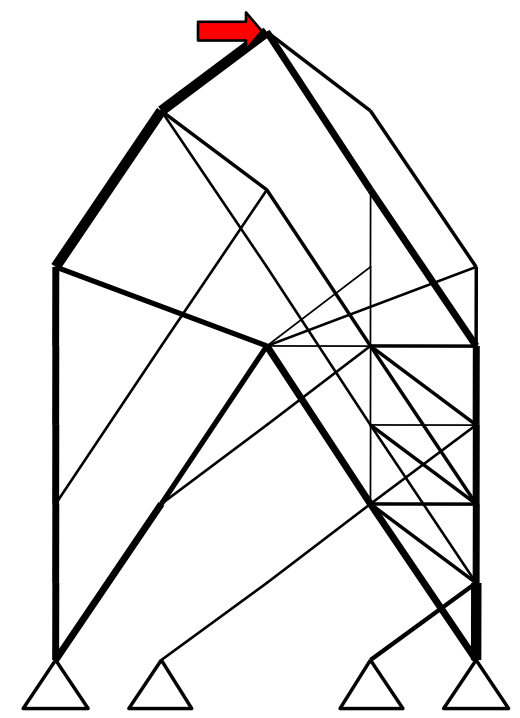

Figure 14. Solution considering buckling for the last example.

The differences between the designs in figures 13 and 14 are significant. We note that left side of the structure, which primarily transfers loads under tension, has more material. This shows once again that the final design using our proposed method tends to concentrate material in the tension members for efficiency. In addition, new load paths can be identified, and the compressive side of the structure includes bracings to reduce the risk of buckling.

\section{Conclusion}

An algorithm is presented for handling imperfection in nodal locations and buckling of truss members. The examples show how the optimized solutions include bracing for compressed members to resist potential buckling. It 
can be shown that the method is computationally efficient, particularly when compared with Monte Carlo or other simulation methods. Further research is being conducted to extend the method to second-order buckling analysis.

\section{Acknowledgments}

This work was supported by the National Science Foundation under Grant No. CMMI-0928613 with Dr. Christina Bloebaum serving as program officer. This support is gratefully acknowledged.

\section{References}

${ }^{1}$ Neves, M. M., Rodrigues, H. C., and Guedes, J.M., “Generalized topology design of structures with a buckling load criterion” Structural and multidiscipline optimization Journal, Vol.10, No. 2, 1995, pp. 71,78.

${ }^{2}$ Ben-Tal A, Jarre F, Kocvara M, Nemirovski A, Zowe J., "Optimal design of trusses under a nonconvex global buckling constraint,” Journal of Optimization and Engineering, Vol. 1, No. 2, 2000, pp.189, 213.

${ }^{3}$ Stolpe, M., "Global optimization of minimum weight truss topology problems with stress, displacement, and local buckling constraints using branch-and-bound,” International Journal for Numerical Methods in Engineering Vol. 61, 2004, pp. 1270, 1309.

${ }^{4}$ Duysinx P, Bendsøe MP., “Topology optimization of continuum structures with local stress constraints,” International Journal for Numerical Methods in Engineering, Vol. 43, 1998, pp. 1453,1478.

${ }^{5}$ Kirsch U., "Integration of reduction and expansion process in layout optimization," Structural and multidiscipline optimization Journal Vol. 11, No. 1-2, 1996, pp. 13, 18.

${ }^{6}$ Guo X., Cheng G. D., and Olhoff N., “Optimum design of truss topology under buckling constraints," Structural and multidiscipline optimization Journal, Vol. 30, No. 3, 2005, pp. 169, 180.

${ }^{7}$ Rozvany G. I. N., "Difficulties in truss topology optimization with stress, local buckling and system stability constraints," Structural and multidiscipline optimization Journal, Vol. 11, No. 3-4, 2003, pp. 213, 217.

${ }^{8}$ Zhou M., "Difficulties in truss topology optimization with stress and local buckling constraints," Structural and multidiscipline optimization Journal, Vol. 11, No. 1-2, 1996, pp. 134, 136.

${ }^{9}$ Bendsøe M.P., Sigmund O., Topology Optimization: Theory, Methods, and Applications, $2^{\text {nd }}$ ed., Springer, Berlin, 2003.

${ }^{10}$ Bendsøe M.P., Ben-Tal A., Zowe J., "Optimization methods for truss geometry and topology design”, Structural and multidiscipline optimization Journal, Vol. 7, No. 3, 1994, pp. 141,159.

${ }^{11}$ Diaz A., Bendsøe M.P., "Shape optimization of structures for multiple loading conditions using a homogenization method" , Structural and multidiscipline optimization Journal, Vol.4, No.1, 1992, pp. 17,22.

${ }^{12}$ Ben-Tal A., Nemirovski A., "Robust truss topology design via semi definite programming”, SIAM Journal on optimization, Vol. 7, Issue 4, 1997, pp. 991,1016.

${ }^{13}$ Guest J.K., Igusa T., "Structural optimization under uncertain loads and nodal locations,” Computer Methods in Applied Mechanics and Engineering Vol. 198, No. 1., 2008, pp. 116, 124.

${ }^{14}$ Asadpoure A., Guest J.K., Igusa T., "Structural topology optimization considering correlated uncertainties in elastic modulus," Collection of Technical Papers - AIAA/ASME/ASCE/AHS/ASC Structures, Structural Dynamics and Materials Conference. AIAA, Orlando, FL, Article Number 2010-2943:1-8, 2010.

Post-print prepared by MSL Academic Endeavors, the imprint of the Michael Schwartz Library at Cleveland State University, 2014 